\title{
Possible role of imatinib in clinical pulmonary veno-occlusive disease
}

\author{
M.J. Overbeek*, G.P. van Nieuw Amerongen\# , A. Boonstra*, E.F. Smit* \\ and A. Vonk-Noordegraaf*
}

ABSTRACT: The platelet-derived growth factor receptor inhibitor imatinib has demonstrated clinical and haemodynamical improvement in both animal models of pulmonary hypertension (PH) and patients with $\mathrm{PH}$. It has been suggested that anti-proliferative effects on pulmonary vascular smooth muscle cells are responsible for these beneficial effects.

The current study describes a patient with pulmonary arterial hypertension associated with a suspected pulmonary veno-occlusive disease.

Treatment with imatinib resulted in rapid clinical improvement and decrease of ground-glass opacities and lobular septal thickening on high-resolution computed tomography.

Based on these findings and on in vitro effects of imatinib on permeability of the endothelium, the authors hypothesise that the rapid clinical outcome is partly due to effects of imatinib on vascular integrity.

KEYWORDS: Imatinib, platelet-derived growth factor receptor, pulmonary arterial hypertension, pulmonary veno-occlusive disease, vascular permeability

\section{CASE REPORT}

A 56-yr-old female was referred to the VU University Medical Center (Amsterdam, the Netherlands) for the evaluation of pulmonary hypertension. The patient's medical history included tuberculosis at the age of $12 \mathrm{yrs}$, which was treated with para-aminosalicylate, hypothyroidism and a smoking history of 7 pack-yrs. Prior to referral, the patient had been hospitalised elsewhere and diagnosed with pneumonia. Due to her complaint of progressive dyspnoea for 15 months, and following the diagnosis of idiopathic pulmonary arterial hypertension (PAH) in her sister $1 \mathrm{yr}$ earlier, an echocardiogram was performed, which demonstrated an elevated pulmonary artery systolic pressure of $50 \mathrm{mmHg}$.

The patient was in functional New York Heart Association (NYHA) class 4. Physical examination revealed a blood pressure of 150/ $110 \mathrm{mmHg}$, a tachycardia of 110 beats $\cdot \mathrm{min}^{-1}$, a tachypnea of $30 \mathrm{breaths} \cdot \mathrm{min}^{-1}$, and a peripheral saturation on pulse oxymeter of $97 \%$ with $15 \mathrm{~L} \cdot \mathrm{min}^{-1} \quad \mathrm{O}_{2}$ delivered by oxygen mask. Laboratory testing demonstrated an arterial oxygen tension $\left(\mathrm{Pa}_{1} \mathrm{O}_{2}\right)$ of $6.52 \mathrm{kPa} \quad(49 \mathrm{mmHg})$. The N-terminal pro brain natriuretic peptide
(NT-proBNP) was $588 \mathrm{ng} \cdot \mathrm{L}^{-1}$ (normal range 0$\left.301 \mathrm{ng} \cdot \mathrm{L}^{-1}\right)$. Autoimmune serology showed weakly positive antinuclear antibodies. Extractable nuclear antigen and antineutrophil cytoplasmic antibody were negative. Pulmonary function testing showed a reduced diffusing capacity of the lung for carbon monoxide $(D \mathrm{~L}, \mathrm{CO})$ of $37 \%$, and a reduced $\mathrm{DL}, \mathrm{CO} /$ alveolar volume of $40 \%$. A high-resolution computed tomography (HRCT) scan revealed thickened septal lines and mosaic ground-glass opacities. There were no signs of pulmonary embolism. An echocardiogram showed normal left ventricular (LV) function.

Pulmonary hypertension (PH) was confirmed by right heart catheterisation, revealing a pulmonary arterial systolic pressure of $102 \mathrm{mmHg}$, a pulmonary arterial diastolic pressure of $40 \mathrm{mmHg}$ and a mean pulmonary arterial pressure of $69 \mathrm{mmHg}$. The mean right atrial pressure was $9 \mathrm{mmHg}$. The pulmonary capillary wedge pressure (PCWP) was $12 \mathrm{mmHg}$. There was a mixed venous saturation of $59 \%$, a cardiac output of $3.0 \mathrm{~L} \cdot \mathrm{min}^{-1}$ and a pulmonary vascular resistance of 1,497 dynes $\cdot \mathrm{s}^{-1} \cdot \mathrm{cm}^{-5}$. Systemic blood pressure during right heart catheterisation was

\section{AFFILIATIONS}

Depts of *Pulmonary Diseases, and \#Physiology, VU University Medical Center, Amsterdam, The Netherlands.

\section{CORRESPONDENCE}

A. Vonk-Noordegraaf

Dept of Pulmonary Diseases

VU University Medical Center De Boelelaan 1117

P.0. Box 7057

1007 MB Amsterdam

The Netherlands

Fax: 31204444328

E-mail: A.Vonk@vumc.nl

Received:

May 062007

Accepted after revision:

December 102007

SUPPORT STATEMENT

G.P. van Nieuw Amerongen was supported by a grant from the Netherlands Heart Foundation (T2003-0032).

STATEMENT OF INTEREST

None declared. 

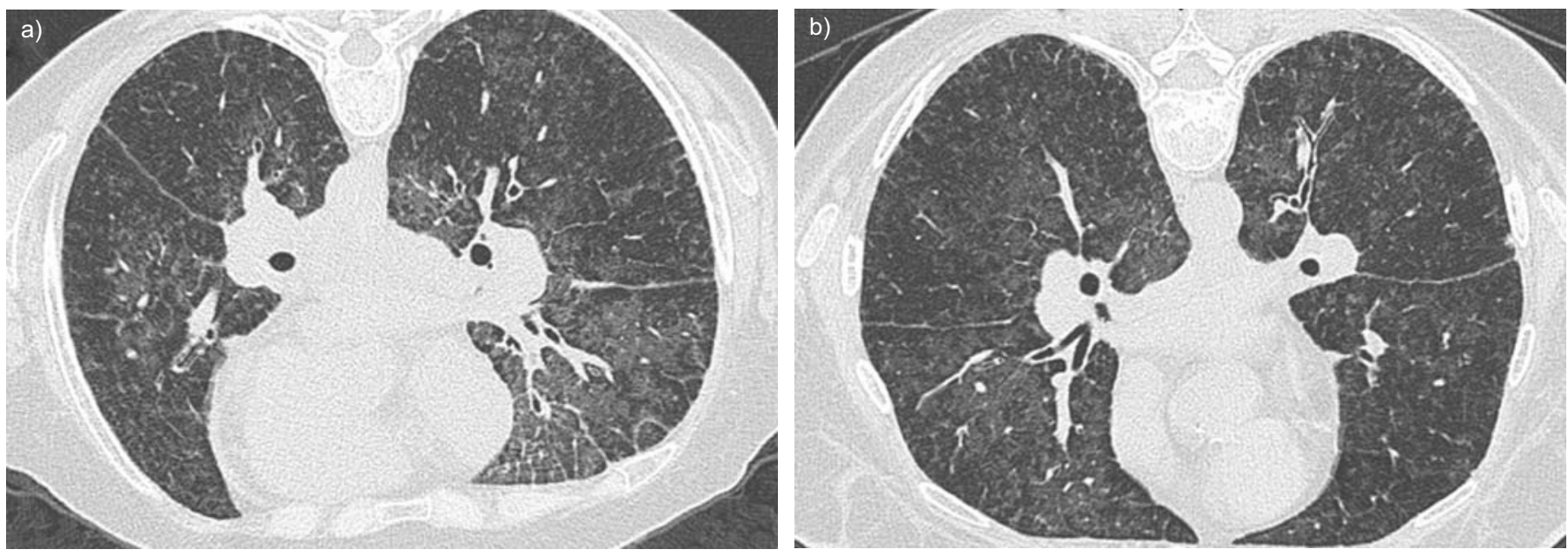

FIGURE 1. High-resolution computed tomography scan of the lung, demonstrating a) thickened lobular septal lines and patchy mosaic ground-glass opacities before treatment with imatinib and b) persisting ground-glass opacities but decreased lobular septal thickening after initiation of imatinib.

$102 / 40 \mathrm{mmHg}$. No testing on acute vasodilator response was performed.

The findings of the HRCT, together with the low DL,CO and oxygen content and the normal PCWP, are compatible with pulmonary veno-occlusive disease (PVOD), a rare variant of PAH. This pattern was similar to that of the patient's sister, thus familial PVOD was suspected, a phenomenon scarcely reported in the literature $[1,2]$. The patient's condition was considered a contraindication to performing an open lung biopsy for diagnostic confirmation. Genetic screening on exonic and flanking intronic regions revealed no Bone Morphogenetic Protein Receptor (BMPR)2 gene mutations.

Treatment was initiated with the prostacyclin analogue epoprostenol at a dose of $13 \mathrm{ng} \cdot \mathrm{kg}^{-1} \cdot \mathrm{min}^{-1}$, loop diuretics and anticoagulation. No clinical improvement was observed and the epoprostenol dose was increased gradually to $23 \mathrm{ng} \cdot \mathrm{kg}^{-1} \cdot \mathrm{min}^{-1}$ over 4 months resulting in modest clinical improvement. The patient deteriorated 8 months after diagnosis of $\mathrm{PH}$, reporting progressive dyspnoea, loss of appetite, weight loss of $23 \mathrm{~kg}$ in the previous 4 months and an inability to perform minimal physical activities, such as combing her hair. Epoprostenol was increased to $25 \mathrm{ng} \cdot \mathrm{kg}^{-1} \cdot \mathrm{min}^{-1}$ and diuretic treatment was intensified with a total dose of $200 \mathrm{mg}$ furosemide. There was no clinical improvement and, 2 weeks after increment of epoprostenol, the patient was hospitalised again. At that time the patient was again in NYHA class 4 , requiring a high dose of oxygen; the peripheral saturation was $87 \%$ with $7 \mathrm{~L} \cdot \mathrm{min}^{-1} \mathrm{O}_{2}$. There was a renal insufficiency with a glomerular filtration rate of $30 \mathrm{mg} \cdot \mathrm{min}^{-1}$. The NT-proBNP had increased to $4,443 \mathrm{ng} \cdot \mathrm{L}^{-1}$. A repeated HRCT scan showed progression of septal thickening and ground-glass opacities (fig. 1a). Epoprostenol dose was decreased on the first 3 days from $25 \mathrm{ng} \cdot \mathrm{kg}^{-1} \cdot \mathrm{min}^{-1}$ to $22 \mathrm{ng} \cdot \mathrm{kg}^{-1} \cdot \mathrm{min}^{-1}$. Again there was no clinical improvement. Although additional effects of sildenafil and/or bosentan to epoprostenol could not be excluded, it was not expected that these drugs would result in a prompt, timely reversal of the devastating clinical condition of the patient. Therefore, it was decided that the patient should be treated experimentally with imatinib (Gleevec $\mathbb{}$; Novartis Pharma, Arnhem, the
Netherlands), a tyrosine kinase inhibitor directed against the platelet-derived growth factor receptor (PDGFR). The decision was also based on an avialable case report of imatinib treatment of $\mathrm{PH}$ [3] and data concerning upregulation of PDGFR genes in pulmonary capillary haemangiomatosis $(\mathrm{PCH})$ [4]. Imatinib treatment was started at a dose of $200 \mathrm{mg}$ daily, initiated on the third day of hospitalisation. Within $24 \mathrm{~h}$ the patient reported improvement of dyspnoea. The peripheral saturation was $94 \%$ with $7 \mathrm{~L} \cdot \mathrm{min}^{-1} \mathrm{O}_{2} \cdot \mathrm{Pa}_{1} \mathrm{O}_{2}$ increased from $6.52 \mathrm{kPa}(49 \mathrm{mmHg})$ to $8.25 \mathrm{kPa}(62 \mathrm{mmHg})$. The patient regained her appetite and was able to perform light daily activities independently. The peripheral saturation was $100 \%$ with $5 \mathrm{~L} \cdot \mathrm{min}^{-1} \mathrm{O}_{2}, 3$ days after initiation of imatinib.

A third HRCT scan, 1 month later, showed partial resolution of ground-glass opacities and septal thickening (fig. 1b). Meanwhile, the NT-proBNP level had fallen to $886 \mathrm{ng} \cdot \mathrm{L}^{-1}$. During a $6-\mathrm{min}$ walking distance test she was able to walk $346 \mathrm{~m}$.

The patient was still clinically stable on epoprostenol at $22 \mathrm{ng} \cdot \mathrm{kg}^{-1} \cdot \mathrm{min}^{-1}$ and imatinib at $200 \mathrm{mg}$ b.i.d. 12 months after initiation of imatinib. Haemodynamic evaluation was refused by the patient. However, she reported symptomatic improvement and was in NYHA class 3 and was able to perform light activities without oxygen supplementation. $\mathrm{Pa}_{\mathrm{a}} \mathrm{O}_{2}$ remained stable at $9.18 \mathrm{kPa}(69 \mathrm{mmHg})$ and $8.51 \mathrm{kPa}(64 \mathrm{mmHg})$, after 1 and 7 months of imatinib treatment, respectively. Besides alopecia the patient has not reported side effects that could be ascribed to the use of imatinib.

\section{DISCUSSION}

To the current authors' knowledge, this is the first study to show beneficial effects of imatinib in a patient with characteristic features of PVOD. PVOD is a rare form of PAH that affects post-capillary vessels by occlusion of pulmonary venules and veins by fibrous tissue, and by arterialisation characterised by the development of muscularised media [5-7]. An important histopathological feature is interstitial oedema, radiographically represented by the patchy ground-glass opacities and the thickened septal lines on HRCT scans, especially in the lobular septa. 
The diagnosis of PVOD could not be proven histologically in this patient. However, there are several arguments for this diagnosis, such as the normal PCWP, the characteristic radiological features, the low $D \mathrm{~L}, \mathrm{CO} /$ alveolar volume and the familial aspect of the disease presentation [6]; whereas arguments for familial PAH are weakened by the negative BMPR2 gene screening. Based on the clinical findings, the diagnosis of $\mathrm{PCH}$ cannot be excluded. However, it remains questionable whether both conditions should be considered as different diseases or rather as histological variants of a single disease [8]. Underlying LV pathology seems less probable considering the normal PCWP, the normal LV function on echocardiogram and the familial occurrence of PH. Sarcoid vasculopathy should be considered in the differential diagnosis, as similar radiological features and diffusion abnormalities may occur [9]; however, in this case the familial occurrence and the absence of extrapulmonary sarcoidosis make this diagnosis less likely.

Imatinib still has an experimental status in the treatment of $\mathrm{PH}$ and should not be used outside reference centres for $\mathrm{PH}$ treatment. Several examples of imatinib treatment of $\mathrm{PH}$ in exceptional cases have now been published, in which improvement of clinical status, exercise capacity and haemodynamics resulted [3, 10, 11]. In the present study patient, clinical status and exercise capacity improved as well. A right heart catheterisation, to support the observed effect of imatinib with haemodynamic data, could not be performed. However, the NT-proBNP level showed a marked decrease after initiation of imatinib treatment. This suggested improvement of haemodynamic parameters, as several recent studies have shown a relationship between NT-proBNP levels and right ventricular function in patients with PAH [12-14].

Imatinib is a tyrosine kinase inhibitor directed against several receptor tyrosine kinases including PDGFR, the tyrosine kinase $\mathrm{C}-\mathrm{KIT}$ and the tyrosine kinase domain of the breakpoint cluster region $(\mathrm{BCR}) /$ Abelson murine leukaemia (ABL) fusion protein. Whereas the role of $\mathrm{c}-\mathrm{KIT}$ and $\mathrm{BCR} / \mathrm{ABL}$ in the pathogenesis of $\mathrm{PH}$ has not been studied, a role of PDGFR in $\mathrm{PH}$ has been suggested in vivo by SCHERMULY et al [15]. In animal models of monocrotaline-induced $\mathrm{PH}$ in rats and chronically hypoxic mice with established $\mathrm{PH}$, the administration of imatinib led to reversal of pulmonary vascular remodelling, $\mathrm{PH}$ and right-sided heart hypertrophy. Interestingly, the $P D G F B$ and $P D G F R-\beta$ genes have been demonstrated to be upregulated in the nodules of proliferating capillaries of $\mathrm{PCH}$ lesions, which could occur secondarily to PVOD $[4,8]$.

The mechanism of action of imatinib in the present patient is merely speculative. Besides the previously described antiproliferative effects, which might have caused the long-term clinical improvement, vasodilation might have played a role as well, although such an effect of imatinib on the pulmonary vasculature has not been described.

Of particular interest in the present case is that treatment with imatinib led not only to immediate clinical improvement, but also to a decrease in septal thickening on the HRCT scan. It is tempting to speculate that the rapid improvement was caused by some other process, such as resolution of pulmonary oedema. This might be partially explained by an effect of the integrity of the endothelial layer, as there are indications from in vitro studies that platelet-derived growth factor and/or imatinib exert influence on the endothelial vascular integrity $[16,17]$. Rapid resolution of oedema was unexpected, as a wellknown side-effect of inhibition of PDGFR signalling in tumour patients is an increase in fluid retention due to normalisation of elevated interstitial fluid pressures $[18,19]$.

In conclusion, the present study presents a patient with suspected, severely deteriorating pulmonary veno-occlusive disease, who demonstrated rapid clinical improvement and stabilisation after addition of imatinib to epoprostenol treatment. The authors speculate that in addition to the antiproliferative effects of imatinib, imatinib also diminished pulmonary oedema formation by improving the integrity of the endothelial lining or reducing the hydrostatic capillary pressure, and thus contributed to the rapid clinical and radiographical improvement of the patient.

\section{REFERENCES}

1 Davies P, Reid L. Pulmonary veno-occlusive disease in siblings: case reports and morphometric study. Hum Pathol 1982; 13: 911-915.

2 Voordes CG, Kuipers JR, Elema JD. Familial pulmonary veno-occlusive disease: a case report. Thorax 1977; 32: 763-766.

3 Ghofrani HA, Seeger W, Grimminger F. Imatinib for the treatment of pulmonary arterial hypertension. $N$ Engl J Med 2005; 353: 1412-1413.

4 Assaad AM, Kawut SM, Arcasoy SM, et al. Platelet-derived growth factor is increased in pulmonary capillary hemangiomatosis. Chest 2007; 131: 850-855.

5 Heath D, Segel N, Bishop J. Pulmonary veno-occlusive disease. Circulation 1966; 34: 242-248.

6 Mandel J, Mark EJ, Hales CA. Pulmonary veno-occlusive disease. Am J Respir Crit Care Med 2000; 162: 1964-1973.

7 Wagenvoort CA, Wagenvoort N, Takahashi T. Pulmonary veno-occlusive disease: involvement of pulmonary arteries and review of the literature. Hum Pathol 1985; 16: 10331041.

8 Lantuejoul S, Sheppard MN, Corrin B, Burke MM, Nicholson AG. Pulmonary veno-occlusive disease and pulmonary capillary hemangiomatosis: a clinicopathologic study of 35 cases. Am J Surg Pathol 2006; 30: 850-857.

9 Nunes H, Humbert M, Capron F, et al. Pulmonary hypertension associated with sarcoidosis: mechanisms, haemodynamics and prognosis. Thorax 2006; 61: 68-74.

10 Patterson KC, Weissmann A, Ahmadi T, Farber HW. Imatinib mesylate in the treatment of refractory idiopathic pulmonary arterial hypertension. Ann Intern Med 2006; 145: 152-153.

11 Souza R, Sitbon O, Parent F, Simonneau G, Humbert M. Long term imatinib treatment in pulmonary arterial hypertension. Thorax 2006; 61: 736.

12 Gan CT, McCann GP, Marcus JT, et al. NT-proBNP reflects right ventricular structure and function in pulmonary hypertension. Eur Respir J 2006; 28: 1190-1194.

13 Andreassen AK, Wergeland R, Simonsen S, Geiran O, Guevara C, Ueland T. N-terminal pro-B-type natriuretic 
peptide as an indicator of disease severity in a heterogeneous group of patients with chronic precapillary pulmonary hypertension. Am J Cardiol 2006; 98: 525-529.

14 Fijalkowska A, Kurzyna M, Torbicki A, et al. Serum Nterminal brain natriuretic peptide as a prognostic parameter in patients with pulmonary hypertension. Chest 2006; 129: 1313-1321.

15 Schermuly RT, Dony E, Ghofrani HA, et al. Reversal of experimental pulmonary hypertension by PDGF inhibition. J Clin Invest 2005; 115: 2811-2821.

16 Harhaj NS, Barber AJ, Antonetti DA. Platelet-derived growth factor mediates tight junction redistribution and increases permeability in MDCK cells. J Cell Physiol 2002; 193: 349-364.
17 Kurimoto N, Nan YS, Chen ZY, et al. Effects of specific signal transduction inhibitors on increased permeability across rat endothelial monolayers induced by neuropeptide Y or VEGF. Am J Physiol Heart Circ Physiol 2004; 287: H100-H106.

18 Jayson GC, Parker GJ, Mullamitha S, et al. Blockade of platelet-derived growth factor receptor- $\beta$ by CDP860, a humanized, PEGylated di-Fab', leads to fluid accumulation and is associated with increased tumor vascularized volume. J Clin Oncol 2005; 23: 973-981.

19 Pietras K, Ostman A, Sjoquist M, et al. Inhibition of platelet-derived growth factor receptors reduces interstitial hypertension and increases transcapillary transport in tumors. Cancer Res 2001; 61: 2929-2934. 